\title{
Behavioral Associations of Neuronal Activity in the Ventral Tegmental Area of the Rat
}

\author{
Ann E. K. Kosobud,' Glenda C. Harris, ${ }^{2}$ and John K. Chapin' \\ 'Department of Physiology and Biophysics and 'Department of Behavioral Neuroscience, Hahnemann University, \\ Philadelphia, Pennsylvania 19102
}

\begin{abstract}
The ventral tegmental area (VTA) is a central element in a system that mediates the reinforcing properties of natural stimuli (such as food), brain stimulation, and drugs of abuse. Although considerable effort has been applied to understanding how drugs of abuse influence this system, relatively little work has examined its function during conditioned reinforcement tasks in awake, behaving animals. In the present studies, bundles of four to eight microwire electrodes were chronically implanted in the VTA or prefrontal cortex (PFC) of male Wistar rats. Following recovery from surgery, simultaneous recordings from multiple single neurons and unit clusters were obtained in rats pressing a lever for a sucrose solution on a fixed-ratio schedule of reinforcement. Consistent with the hypothesis that these neurons encode information related to motivation, most of the neurons in both VTA and PFC showed significant modulation of firing rate associated with one or more events occurring within the response/reinforcement cycle. These events included lever presses, onset and end of a tone signaling sucrose delivery, and onset and end of sucrose consumption. Significant decreases in firing rate were observed, coincident with onset of the tone and sucrose delivery, or with consumption. These decreases were sustained through the end of sucrose consumption. A number of neurons also discharged bursts of activity associated with individual lever presses. These findings provide a clear demonstration that VTA neuronal activity is modulated during motivated behavior. Similar information about events within the ongoing response/reinforcement cycle appears to be distributed through many neurons within the VTA, and may be mirrored in target structures such as PFC.
\end{abstract}

[Key words: reward, dopamine, single-unit recording, freely moving, prefrontal cortex, behavior, ventral tegmental area]

The ventral tegmental area (VTA) is the source of dopaminergic projections that supply a system of structures in ventral forebrain and frontal association cortex. This group of structures, known collectively as the mesocorticolimbic dopamine system,

Received Nov. 11, 1993; revised Apr. 29, 1994; accepted May 26, 1994.

This work was supported by NIII Grants NS26722, AA06965, KO2-AA00089, Air Force Grant AFOSR 90-0266, and Hahnemann University RIG 990414. We thank Drs. David Kareken, Brian Clark, and Patricia Cowell for their comments on the manuscript.

Correspondence should be addressed to Ann Kosobud, Ph.D., Department of Physiology and Biophysics, Hahnemann University, MS 409, Broad and Vine, Philadelphia, PA 19102-1192.

Copyright (C) 1994 Society for Neuroscience $0270-6474 / 94 / 147117-13 \$ 05.00 / 0$ has been implicated in motivated behavior (for review, see Wise and Rompre, 1989). Increases in DA utilization and concentration, respectively, have been reported during food consumption (Heffner et al., 1980), and during presentation of signals predicting delivery of a meal (Phillips et al., 1991). This systcm is generally considered to play a role in secondary or tertiary aspects of goal directed behavior, such as preparation, organization, and initiation (Phillips et al., 1991; Salamone, 1991). For example, moderate reductions of mesocorticolimbic dopamine disrupt hoarding and foraging (Blundell et al., 1977; Le Moal et al., 1977; Panksepp, 1982), responses to cues predicting food (Blackburn et al., 1986, 1987, 1989a,b), and responses to conditioned reinforcers (Clody and Carlton, 1980), without affecting food or water intake.

The reinforcing actions of drugs of abuse also appear to be mediated through the VTA/NAc system. For instance, amphetamine (Hoebel et al., 1983) and morphine (Olds, 1982; Goeders et al., 1984) are self-administered directly to the nucleus accumbens (NA). Peripheral administration of neuroleptics attenuates or blocks the rewarding effects of amphetamine (Yokel and Wise, 1975) and cocaine (de Wit and Wise, 1977). Destruction of DA terminals within the NA attenuates or blocks self-administration of cocaine (Roberts et al., 1977) and amphetamine (Lyness et al., 1979) as well as morphine (Bozarth and Wise, 1986; but see Pettit et al., 1984). Finally, metabolism or turnover of DA within the NA is enhanced by $\mu$-agonist opioids (Spanagel et al., 1990, 1991), THC (Chen et al., 1993), cocaine (Goeders and Smith, 1993), ethanol (Imperato and Di Chiari, 1986; Yoshimoto et al., 1992), amphetamine (Carboni et al., 1989), and nicotine (Imperato et al., 1986). Note, however, that elevated DA levels in the NA are also associated with stress (Thierry et al., 1976), and after administration of the anxiogenic drugs $\beta$-CCE and FG 7142 (McCullough and Salamone, 1992), suggesting these levels reflect a quantitative rather than qualilative property of motivation.

Though the VTA has been a frequent subject for in vivo neurophysiological recording studies in anesthetized rats, relatively few studies have attempted to address information processing in this region in awake animals, and fewer still have looked during motivated behaviors. Investigators recording from VTA DA neurons have observed increased activity and bursts related to orienting responses, exploratory behavior, and events with motivational significance (Trulson and Preussler, 1984; Freeman and Bunney, 1987). DA ncurons in the VTA and substantia nigra respond to stimuli with alerting, activating, and rewardrelated properties (Schultz, 1986; Romo and Schultz, 1989; Ljungberg et al., 1992; Schultz et al., 1993). The non-DA neu- 
rons of the VTA have received even less attention, although their activity appears related to changes in DA function. NonDA neurons increase their firing rate coincident with locomotion stimulated by amphetamine and apomorphinc (Olds, 1988a,b), and to enhanced DA metabolism in the NA (Olds, 1991).

One reason for the paucity of studies may be the difficulty in interpretation of data obtained from consecutive recordings of single units. Not only are simultaneous recordings from multiple units more efficient, increasing the data yield for each animal, but the parallel recordings provide controls against the potential nonstationarity of unit activity recorded during lengthy behavioral experiments. Thus, the data from simultaneously recorded neurons provide a better estimate of the information present within a functional group of neurons.

In the present study, VTA unit activity was recorded in rats performing a simple task (lever pressing for access to sucrose solutions). Firing rates were evaluated relative to specific events, including (1) lever pressing, (2) a tone signaling sucrose delivery, and (3) sucrose consumption. Because these events typically occurred at varying times rclativc to cach other, we were able to evaluate which of the above events were most strongly associated with the unit discharge. The specific questions we wished to address were (1) whether modulations of the firing rate of these neurons reflected the ongoing behaviors associated with the operant task, (2) if present, the specific pattern such modulation took, and (3) what the pattern suggested about the nature of information coded in VTA neurons.

\section{Materials and Methods}

Subjects. Adult, male Wistar rats (Charles River Laboratory), weighing $350-450 \mathrm{gm}$ at time of surgery, were housed individually and maintained on a $14 \mathrm{hr}$ on $/ 10 \mathrm{hr}$ off light/dark cycle (lights on 6:00 A.M., off 8:00 P.M.). Water was available ad lib, but food availability was restricted during the training and testing period (discussed below). All animal care and handling was conducted in accordance with the guidelines stated in the Handbook for the Use of Animals in Neuroscience Research (Society for Neuroscience, 1991).

Surgical and histological procedure. The rats were anesthetized with sodium pentobarbital $(50 \mathrm{mg} / \mathrm{kg})$ and placed in a stereotaxic apparatus. The top of the skull was exposed, and a dental drill used to bore small holes for supporting screws and electrode placement. Chronic implants consisted of bundles of four to eight microwire electrodes (Teflon- or Formvar-coated stainless steel, $50 \mu$ diameter), and a stainless steel ground wire connected to 10 pin Microtech connectors. The impedance of the electrodes was $100-200 \mathrm{k} \Omega$ measured at $1 \mathrm{kHz}$. These assemblies were made in-house or purchased from NBLabs (Denison, TX). The bundles were placed either in the medial PFC or VTA using stereotaxic coordinates derived from Paxinos and Watson (1986). The coordinates used for VTA were $-5.0 \mathrm{~mm}$ AP and $0.7 \mathrm{~mm}$ ML to bregma, and 8 $\mathrm{mm} \mathrm{DV}$ to the skull. PFC coordinates were $3.0 \mathrm{~mm} \mathrm{AP}$ and $0.7 \mathrm{~mm}$ ML to bregma, $3.5 \mathrm{~mm}$ DV to the skull. After placement of the electrodes, the plug was permanently attached to the rat's skull and the supporting screws using dental acrylic. At completion of the studies, the rats were anesthetized and the location of recording electrode tips marked by passing a $20 \sec 30 \mu \mathrm{A}$ direct current through selected electrode pairs in each hundle. The rats were then perfused intracardially with physiologic saline followed by a $4 \%$ formaldehyde, $5 \%$ potassium ferrocyanide solution (ferrocyanide creates a green stain at the lesion site by reacting with iron deposits). The brains were removed and stored at $4^{\circ} \mathrm{C}$ in a $4 \%$ formaldehyde/sucrose solution. Frozen sections $(80 \mu \mathrm{m})$ were cut, mounted, and stained with cresyl violet.

Discrimination und recording procedure. For recording, a flexible wire harness was attached to the rat. Each lead in the harness was equipped with a micro FET (field effect transistor) for unity gain current amplification of the signal from each microwire electrode. A second amplification occurred at a preamplifier, and the signal was then carried to a Multi-channel Neuronal Acquisition Processor (MNAP; Spectrum Scientific, Dallas, TX). This system provided direct computer control over amplification, filtering, signal selection, and spike-waveform discrimination and storage for up to 31 channels. In order to suppress low frequency signals (resulting from animal movement or slow potentials in the brain) it was necessary to use a relatively high-frequency bandpass $(0.5-5 \mathrm{kHz})$. As a consequence of this filtering, low-frequency components of long-duration action potentials (such as those exhibited by DAcontaining neurons) were selectively filtered out, resulting in a narrower appearance of the action potential than would have been observed in a less stringently filtered signal.

Action potentials were separated from noise through a set of discriminators allowing specification of windows for both peak amplitude and duration. It was not uncommon to have the activity of more than one ncuron present in the signal on a given wire. This system allowed several independent discriminations to be applied to the same signal, so that the activity of each of the discriminable units could be recorded on an independent channel. In the present studies, three electrodes were found to record two independent, discriminable units, while 13 electrodes recorded only a single discriminable unit. Recordings from electrodes placed in the VTA were obtained from four rats, while one rat provided recordings from electrodes placed in the PFC.

Single neuron versus unit cluster recordings. Two stringent criteria were used to differentiate between single neuron and unit cluster recordings. First, digitized waveforms of all recorded units were obtained and evaluated. In order to be classified as a single neuron, waveforms had to be clearly distinguishable from background activity, and show a consistent pattern with a minimum of variation (Fig. $1 A$, inset). In addition, the firing patterns of these ncurons were examined in autocorrelation histograms (as illustrated in Fig. 1). To create this plot, the time of occurrence of each successive action potential is used as a reference (or "node"), and the temporal distribution of preceding and following action potentials is plotted. This results in a display summarizing the temporal correlation among action potentials within a time series (for a more detailed discussion, see Moore et al., 1966). Single neurons displayed a reduced probability of firing at intervals of less than $10 \mathrm{msec}$, resulting in a trough surrounding the node (Fig. $1 A$ ). This may reflect the normal refractory period of the neuron. In contrast, unit clusters showed nearly equal probability of firing at any time before or after the node, consistent with multiple independent neurons contributing to the recorded activity (Fig. $B$ and inset). While single neuron recordings are necessary for functional characterization of specific neuronal types, unit cluster activity can provide a reliable representation of the physiological information present in a local circuit.

Computer acquisition of spike timing data for multiple neurons. QUNIT, a program running on a Motorola VME multiprocessor computer system, was used for data acquisition and experimental control. With this system, spike timing data from up to 48 units can be continuously collected with a time resolution of $0.2 \mathrm{msec}$. ANALYZE, an off-line neurophysiological data analysis program (written by J.K.C.), was used for analysis, including construction and display of histograms and appropriate quantitative statistical analyses.

Behavioral apparatus, training, and testing. The test chamber consisted of a Plexiglas box, $56 \times 45 \times 18 \mathrm{~cm}$, with access provided by a sliding door. The walls and door had multiple $1.5-\mathrm{cm}$-diameter holes for ventilation, and the floor consisted of a rubber belt. The multichannel commutator was centered in the ceiling. For recording sessions, a flexible wire harness connected from the commutator to the headstage allowing the rat to move and turn freely. On the right wall of the chamber was a panel containing a lever and a spout for liquid delivery.

Beginning 1 week after surgery, rats were habituated to the recording harness and test apparatus, with the lever and spout absent. After 2-3 $\mathrm{d}$ of habituation sessions, the lever and spout were placed in the chamber and lever training begun. At this time, the rat's access to food was limited to a single daily post-session feeding. Body weight was slowly $(<2 \% / d)$ reduced to $90 \%$ of the rat's presurgical free-feeding weight and maintained there throughout testing. In the first training session, a partition confined the rats to the chamber half containing the lever and the spout. Initially, a single press of the lever activated a $2 \mathrm{sec}$ tone, and released a small amount $(0.1 \mathrm{ml})$ of $15 \%(\mathrm{w} / \mathrm{v})$ sucrose solution. The lever could be operated remotely by an observer. Shaping sessions consisted of allowing the rat to explore the chamber, while an observer operated the lever to ensure that each time the rat placed its nose or paw on the lever, the tone sounded and sucrose was delivered. Using this strategy, most rats learned to lever-press in 1-2 $45 \mathrm{~min}$ sessions. Once the behavior was established, the criterion was increased to an FR2, FR3, or FR4 (fixed ratio of 2, 3, or 4 lever presses for each reinforcer), depending 
on which schedule produced the most reliable behavior. The final lever press of a series activated a tone $(1900 \mathrm{~Hz})$ and simultaneously delivered sucrose solution. All sessions were videotaped so that the interval during which the rat was licking the spout to consume the sucrose solution could be determined.

Data analysis. The data gathered included spike times for each single unit and unit cluster, and time of occurrence of events. Specifically, these events included lever presses, tone on and sucrose delivery, and drinking behavior (Fig. 2). For qualitative analysis of the relationship between neural activity and behavior, two types of graphical representation were constructed.

First, perievent histograms that averaged the pattern of neuronal activity around discrete events (or "nodes"), including Tone/sucrose begin, Tone/sucrose end, Drinking begin, Drinking end and lever presses, were plotted. In general, a modulation of the firing rate of a given neuron that is temporally associated with a specific behavioral event suggests involvement of the neuron in coding that behavior. The stronger and sharper the modulation seen related to a given event, the more likely that event approximated the "preferred stimulus" of that neuron. The Kolmogorov-Smirnov one-sample test (Siegal, 1956) was used to detect significant deviations (from an even distribution) in the cumulative frequency distribution of unit activity for the $500 \mathrm{msec}$ interval $(250$ msec before to $250 \mathrm{msec}$ after) around the node.

Second, the means and standard deviations were calculated for firing rates during five behavioral intervals derived from the typical sequence of events occurring during the operant task. These intervals included (1) the interval the animal was engaged in lever pressing (Press); (2) the interval during which the tone was on and sucrose was delivered, but prior to initiation of drinking (Tone/sucrose); (3) the interval during which the animal began drinking while the tone and sucrose presentation continued (TSD); (4) the interval during which the animal continued to drink after presentation of the tone and sucrose ended (Drinking); (5) interval after the animal finished drinking, but had not yet begun the next series of lever presses (Pause).

\section{Results}

Localization and characterization of recorded units. Recordings were obtained from a total of 19 units. Thirteen of these units were recorded from four rats with electrode bundles placed in the VTA, while the remaining six units were recorded in the single rat with a bundle placed in the PFC. Photographs showing the location of electrode bundle tips are shown in Figure 3. The PFC electrodes were located deep in the medial wall, in layers $\mathrm{V}$ and VI. Bundle placements for the four rats with VTA electrodes lay within the region medial to the substantia nigra pars reticulata and medial lemniscus, and dorsolateral to the ventral portion of the fasciculus retroflexus.

The 19 units were recorded from a total of 16 electrodes, of which 13 yielded one unit recording (either a single neuron or a unit cluster), and three yielded two separate unit recordings apiece. Using the criteria outlined in Materials and Methods section (see Fig. 1), nine of these recordings were classified as single neurons and 10 as multiunit cluster recordings (Table 1). Single neuron recordings are necessary for defining physiological characteristics of specific neuronal types. However, if eventrelated modulations in firing rate can be detected, multiunit cluster activity can provide a reliable representation of the physiological information present in a local circuit. Because in these studies, we were principally seeking the behavioral information encoded within neural firing, recordings from multiunit clusters were as useful as those from single neurons.

Quantitative analysis of modulations in firing rates associated with discrete events. For the VTA, significant modulations in fring rate were observed most frequently associated with Drinking begin ( 7 of 13) and Drinking end (7 of 13) (Table 1). Some units also responded to Tone/sucrose begin ( 3 of 13) or Tone/ sucrose end ( 4 of 13), and 2 of 13 units responded to lever

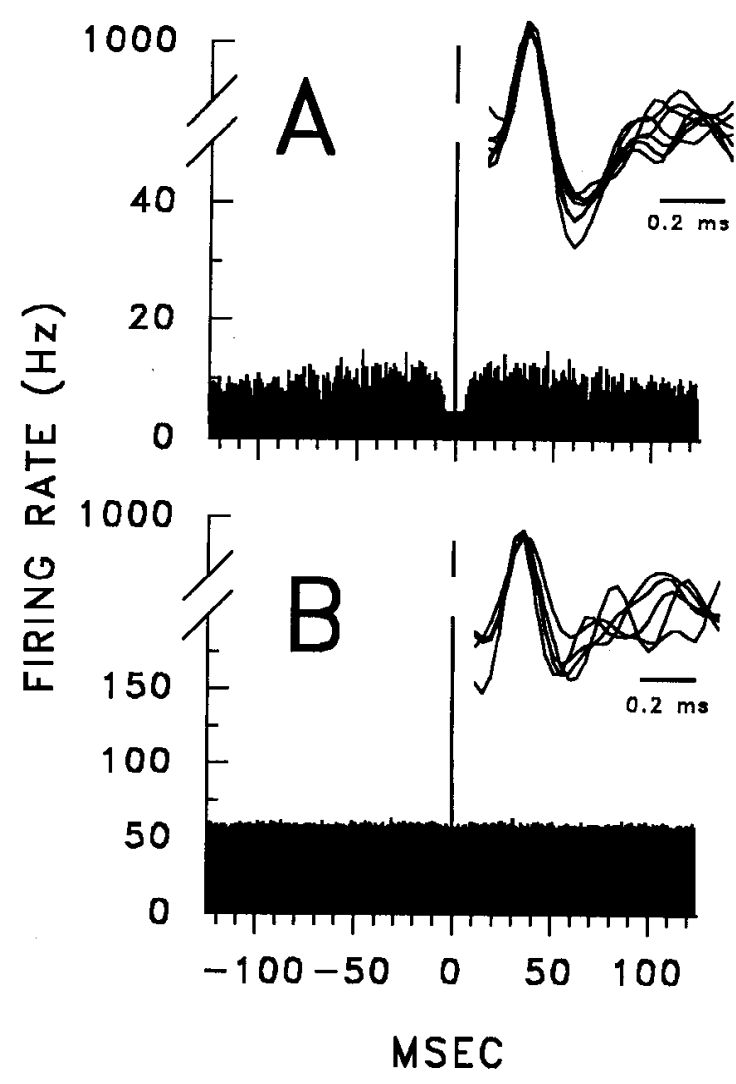

Figure 1. Waveforms and autocorrelation histograms showing typical single neuron and unit cluster recordings. Single neurons had waveforms that were clearly distinguishable from background and showed a minimum of variation (inset, $A$ ). Their autocorrelation histograms displayed a reduced probability of firing at intervals of less than $10 \mathrm{msec}$, resulting in a trough surrounding the node $(A)$. A more heterogeneous waveform, and a random, even distribution in the autocorrelogram, indicate a multiunit recording $(B$, inset).

presses. PFC units showed a slightly different pattern, with more units responding to Tone/sucrose begin ( 3 of 6), Drinking end (3 of 6), and lever presses (3 of 6). Many units responded to more than one event. Even within single neurons, a significant response associated with one event did not predict a response to another. Nor did there appear to be any association between the average firing rate of a given unit and the event-related changes.

Although this approach was adequate for detecting significant changes associated with specific nodes, it did not provide any information about the nature of the change. For instance, the change may have been an increase or a decrease in firing rate, and may have been transient or sustained. To address these issues, qualitative assessment of perievent histograms showing firing patterns relative to discrete events, and graphs showing data averaged through the intervals bounded by these events, were employed.

Construction of perievent histograms and interval averages for qualitative analysis of the relationship between neural activity and events. Figure 4, upper, shows a stripchart displaying $40 \mathrm{sec}$ of recording in a typical experiment, illustrating the temporal distribution among the events (lever presses, reward, and drinking) occurring during the behavioral task. Because the occurrence of each of these events is separated in time, the optimal "behavioral correlate" of each unit could be distinguished by 


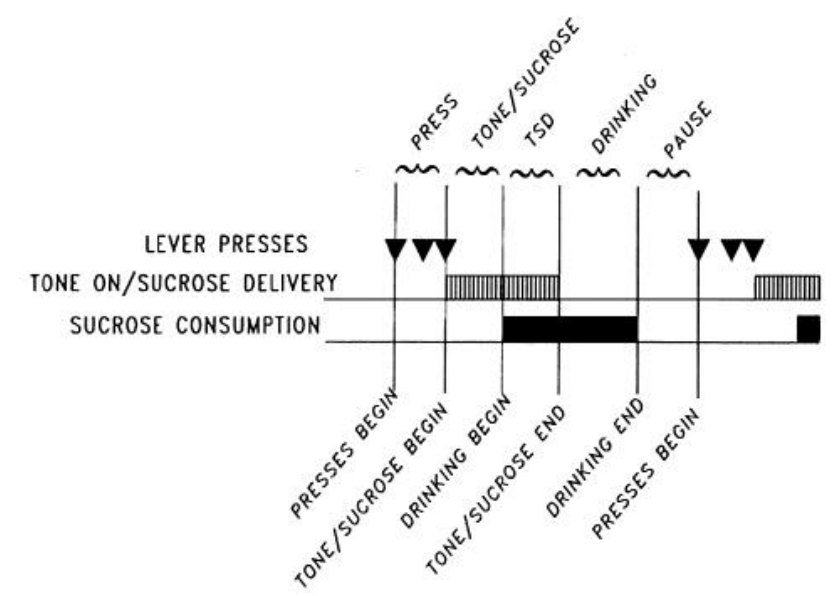

Figure 2. The temporal relationships among events during a free-operant fixed ratio schedule requiring three lever presses to receive reinforcement (FR3). In this example, the third of three lever presses initiates a $1 \mathrm{sec}$ interval during which a $1900 \mathrm{kHz}$ tone sounds, and a valve is open, allowing sucrose solution to drip into a liquid spout within the behavioral chamber. Sucrose consumption was derived from analysis of the videotapes to determine the interval during which the rat was actively licking the spout to consume sucrose solution. For analysis, events could be regarded as points in time associated with brief events or transitions (lever presses, Tone/sucrose begin, Tone/sucrose end, Drinking begin, Drinking end) or intervals (Press, Tone/sucrose, TSD, Drinking, Pause) (see Materials and Methods).

comparing perievent histograms centered around each of these events.

Figure 4, lower, shows the data for 40 repeated cycles of response and reward to illustrate use of such an analysis to reveal the response of a unit to each of four defined events in this behavioral task: Tone/sucrose begin, Drinking begin, Tone/sucrose end, and Drinking end. These four events were used as nodes for alignment of the perievent raster plots and with histograms in the four vertical panels in Figure 5. Within each panel, the first three raster plots show times of all lever presses in a sequence, reward intervals, and drinking intervals, for each of the 40 response/reinforcement cycles. The fourth raster plot shows action potentials of a single unit, which are averaged in the fifth histogram.

A single set of data is repeated in each of the four panels, but the temporal relationship among events varies as a result of organization of the data around the different events. Although the intervals between these events were always not large, the variation in time of occurrence of one event relative to another resulted in a marked difference between the pattern of firing rates relative to events displayed in the bottom four histograms. An examination of these histograms reveals that this neuron shows the sharpest changes in firing rate, and the closest temporal correlation, when Drinking begin is used as the node.

These perievent histograms provided an excellent way to view firing rates relative to specific points in time, but they did not allow analysis of trends in firing rate over time. In order to evaluate sustained changes in firing rates, the cycle of behaviors was broken up into five distinct intervals, and mean and SDs were calculated for those intervals. The first interval (Press) consisted of the time beginning with the first lever press of a sequence and ending with the last. The second interval (Tone/ sucrose) began with the last lever press of a sequence and simultaneous Tone/sucrose begin, and ended with Drinking begin. The third interval (TSD) spanned Drinking begin to Tone/

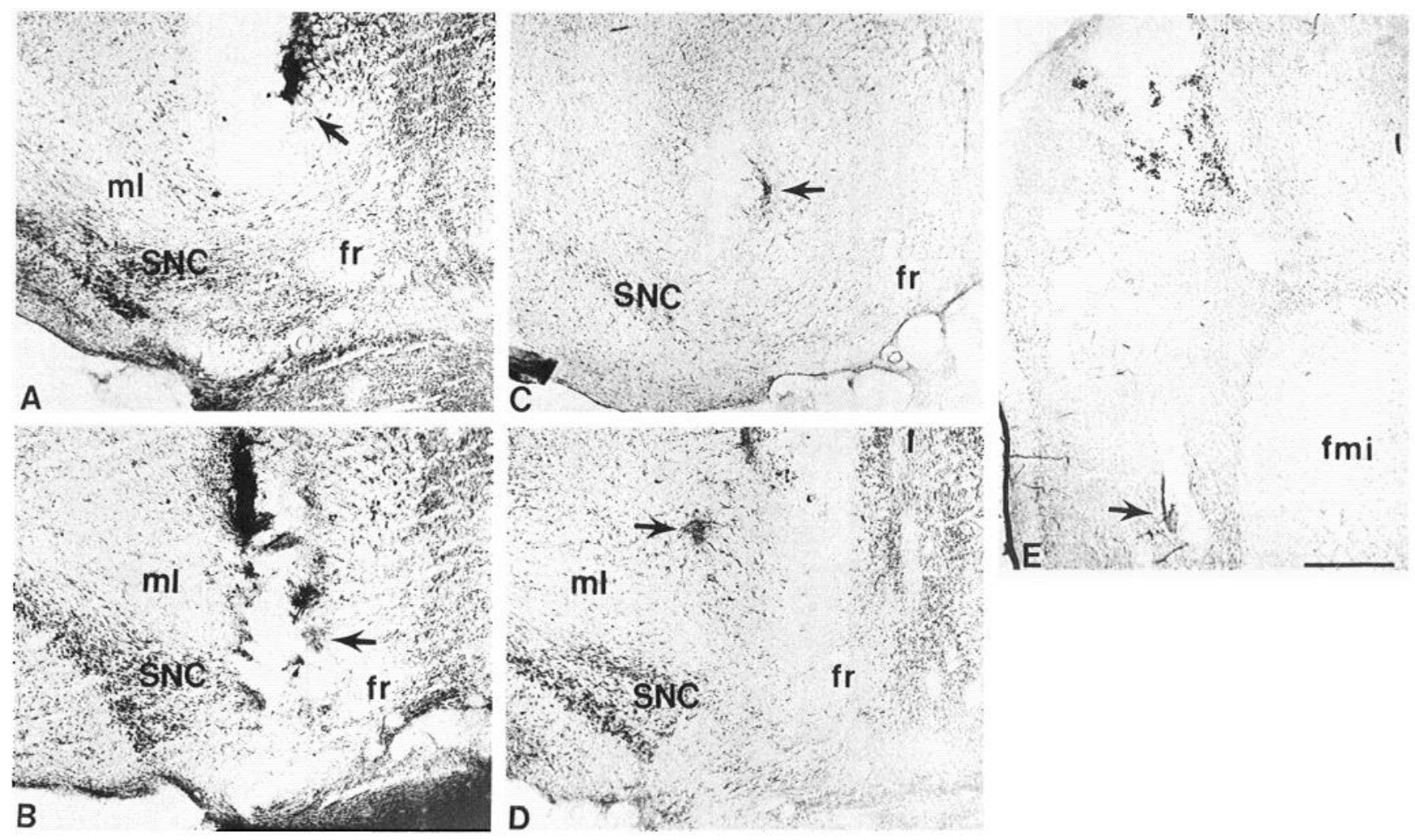

Figure 3. Placement of recording electrodes. Photographs of coronal brain sections showing the placement of bundles in the VTA $(A-D)$ and prefrontal cortex $(E)$. Arrows indicate the location of green staining marking the lesion site. $S N C$, substantia nigra pars compacta; $m l$, medial lemniscus; $f r$, fasciculus retroflexus; fmi, forceps minor of the corpus callosum. 


\begin{tabular}{|c|c|c|c|c|c|c|c|c|}
\hline Rat-unit & $\begin{array}{l}\text { Elec- } \\
\text { trode }\end{array}$ & Category & $\begin{array}{l}\text { Average } \\
\text { rate }\end{array}$ & $\begin{array}{l}\text { Reward } \\
\text { begin }\end{array}$ & $\begin{array}{l}\text { Drinking } \\
\text { begin }\end{array}$ & $\begin{array}{l}\text { Reward } \\
\text { end }\end{array}$ & $\begin{array}{l}\text { Drinking } \\
\text { end }\end{array}$ & $\begin{array}{l}\text { Lever } \\
\text { press }\end{array}$ \\
\hline \multicolumn{9}{|c|}{ Ventral tegmental area } \\
\hline SG1-9 & 12 & Unit cluster & 8.6 & - & - & $*$ & * & - \\
\hline SGI-10 & 11 & Init cluster & 12.0 & $*$ & $*$ & $*$ & * & $*$ \\
\hline SG1-13 & 13 & Unit cluster & 62.6 & - & $*$ & - & * & - \\
\hline SG1-14 & 14 & Unit cluster & 35.4 & - & * & - & * & - \\
\hline S4-1 & 9 & Single neuron & 0.26 & - & $*$ & - & $*$ & - \\
\hline S4-4 & 15 & Single neuron & 0.33 & - & - & - & - & - \\
\hline S4-5 & 16 & Single neuron & 1.24 & $*$ & $*$ & $*$ & - & - \\
\hline W2-13 & 13 & Unit cluster & 0.22 & - & - & - & $*$ & - \\
\hline W2-14 & 14 & Single neuron & 0.54 & $*$ & - & - & * & $*$ \\
\hline P1-6 & 9 & Single neuron & 7.01 & - & $*$ & $*$ & - & - \\
\hline P1-8 & 9 & Single neuron & 1.60 & - & $*$ & - & - & - \\
\hline P1-10 & 10 & Unit cluster & 0.20 & - & - & - & - & - \\
\hline P1-11 & 10 & Single neuron & 0.21 & - & - & - & - & - \\
\hline \multicolumn{9}{|c|}{ Prefrontal cortex } \\
\hline L4- 1 & 2 & Unit cluster & 34.6 & $*$ & - & - & - & $*$ \\
\hline L4-3 & 4 & Unit cluster & 111.8 & * & - & - & $*$ & - \\
\hline L4-4 & 5 & Unit cluster & 74.7 & $*$ & $*$ & - & $*$ & $*$ \\
\hline L4-6 & 9 & Unit cluster & 9.8 & - & - & - & - & - \\
\hline L4-7 & 8 & Unit cluster & 3.1 & - & - & - & $*$ & $*$ \\
\hline L4-8 & 9 & Single neuron & 3.0 & - & - & - & - & - \\
\hline
\end{tabular}

The identifying numbers in the first two columns indicate the rat and discrimination channel, followed by the electrode from which the recording was obtained (some electrodes provided two unit recordings). Unit cluster indicates a recording with two or more units present. Single neuron indicates a recording with only onc unit present or onc unit predominating.

*, significant change associated with the node; -, no significant change associated with the node.

sucrose end, the fourth interval (Drinking) Tone/sucrose end to Drinking end, and the fifth interval (Pause) Drinking end to the first lever press of the next series. Note that none of these intervals can be regarded as a baseline. Rather, the differences between them must be considered relative.

Behavioral associations of neuronal firing rates in the VTA and PFC relative to discrete events and intervals within the operant task. Figures 5-7 display perievent histograms and interval means for the 19 units recorded, averaged over many (151-276) repetitions of the cycle of response and reinforcement present in the operant task. These 19 units were characterized by a great degree of heterogeneity. Nonetheless, the three groupings represented in these figures were intended to highlight some predominant features apparent in the patterns of activity. Figure 5 shows perievent histograms plus interval means and standard deviations for six neurons (all VTA) that showed strong modulations of activity associated principally with reward consumption. Three of these neurons (SG1-13, SG1-14, S4-1) showed statistically significant changes in firing rate within 500 msec of Drinking begin and end (indicated by an asterisk), but not Tone/sucrose begin or end. Examination of the interval means suggests that these significant changes mark the beginning and end of a decrease in firing that lasted throughout reward consumption. For example, for neuron S4-5 (the same neuron for which partial data was presented in Fig. 4), note the difference in the shape of the peak of activity apparent in the perievent histograms constructed around each of the events. This peak lags Tone/sucrose begin by $250-750 \mathrm{msec}$, and its height and sharpness suggest it is much more strongly associated with Drinking begin. Sucrose consumption is accompanied by a dramatic decrease in activity. For this neuron, no significant de- viation in firing rate was detected within $500 \mathrm{msec}$ of Drinking end, but the activity can be seen to increase gradually after consumption ends. Examination of the histograms also suggests that the significant deviation detected at Tone/sucrose end is probably a function of the proximity of this event to Drinking begin. The remaining two units (S4-4, P1-11) did not show statistically significant deviations, but inspection of the pattern of activity present in the histograms and interval averages led to their inclusion with this group of neurons.

The second group of six neurons is shown in Figure 6. These neurons (two PFC, four VTA) showed significant changes in firing rate associated with Tone/sucrose begin and Drinking end. Again, this appeared to result from a relative decrease in activity beginning at Tone/sucrose begin, and maintained until Drinking end.

The remaining seven neurons (Fig. 7) include four that showed only transient changes in firing rate, two that showed no significant changes, and one anomalous VTA unit cluster, SG110. The latter unit cluster showed a unique pattern of activity, with significant responses to all five of the defined behavioral events (see Table 1, Figs. 7, 8), and a dramatic increase in activity during the TSD interval. The length of this interval averaged $1.3 \pm 0.5 \mathrm{sec}($ mean $\pm \mathrm{SD})$. Notc in particular the abrupt cessation of firing that coincides exactly with Tone/sucrose end. Units P1-8, P1-6, and L4-4 showed transient decreases coincident with Drinking begin, and transient increases coincident with Drinking end. Unit L4-7 displayed a transient increase in firing rate coincident with Drinking end. The remaining two neurons (L4-6, L4-8) showed no significant changes associated with any event.

Figure 8 shows five units (three from the PFC and two from 
U

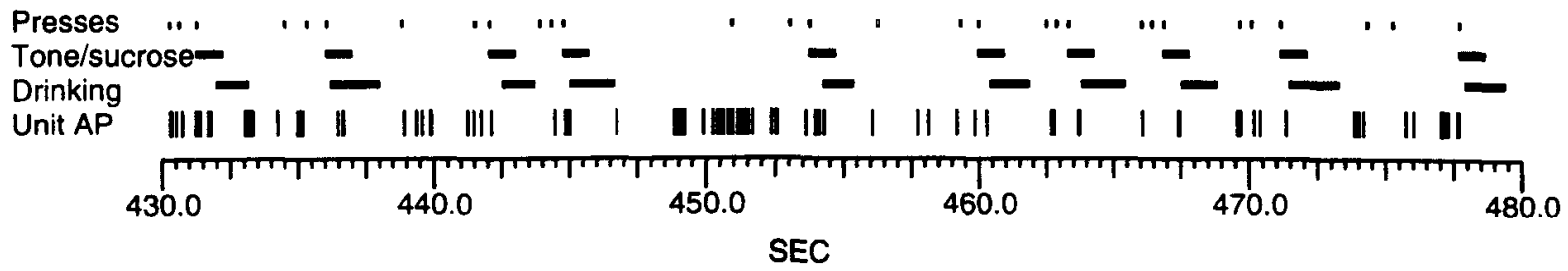
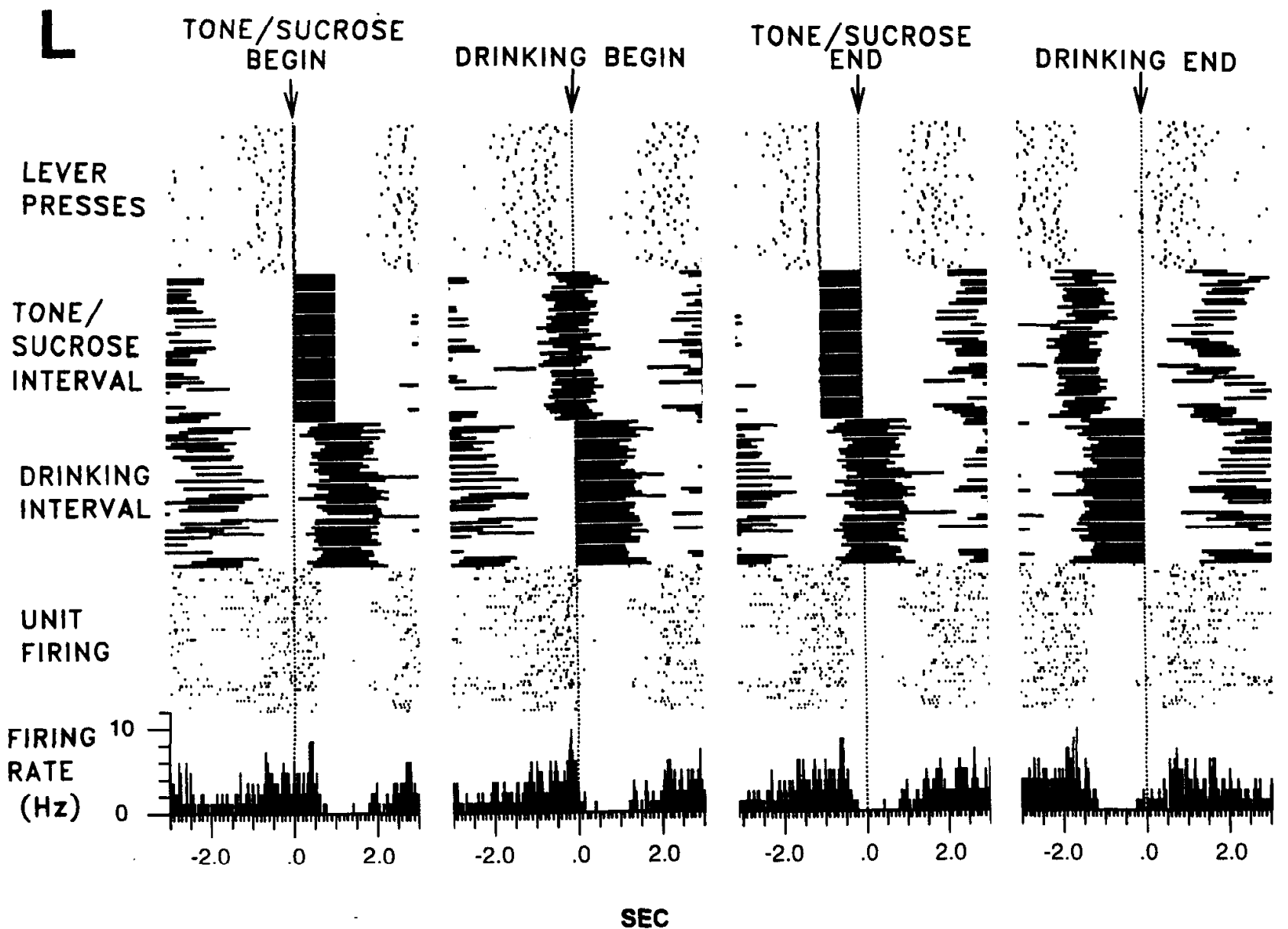

Figure 4. Upper, Stripchart illustrating the typical temporal spacing of events observed in these experiments. The tick marks in the top row indicate the occurrence of lever presses. The horizontal bars in the second row indicate tone on and sucrose delivery. The horizontal bars in the third row indicate consumption intervals (derived from videotapes). The vertical bars in the fourth row indicate the occurrence of action potentials of the recorded unit. To determine whether the recorded units are coding aspects of this behavioral cycle, unit activity is averaged over many repetitions of a behavior (illustrated below). Lower, Perievent histograms using four different events as node. In these graphs, neuronal activity is averaged around a specific event (centered at 0 ) to reveal modulations in firing rate related in time to that event. The top four histograms display lever presses, reward intervals, drinking intervals, and unit firing, respectively. The bottom histogram shows averaged firing rate data. From left to right, the same data are plotted, but the relative occurrence of the events varics because in each panel the data are organized around a different node. The nodal events, indicated at the top of each panel, are displayed in temporal sequence-Tone/sucrose begin, Drinking begin, Tone/sucrose end, Drinking end. Because of the temporal spacing and independence of the various events, a unique pattern of unit activity results from the use of each event as node.

the VTA) that showed transient changes in firing rate associated with lever pressing. Note that the time scale for these responses is much shorter than that used for the previous histograms. Three of these units (L4-1, L4-7, and SG1-10) showed bursts of activity simultaneous with the lever press, consistent with motor or "feedforward" activation. The other two units showed bursts that slightly (W2-14) or unquestionably (L4-4) lagged the lever press, suggesting they might reflect sensory responses or "feedback" activation associated with the click of the lever.
More PFC units ( 3 of 6 ) showed lever press responses than VTA units ( 2 of 13). In all cases, units that responded to one lever press responded to all lever presses; there was no detectable distinction between the first, last or intervening lever presses in a series.

\section{Discussion}

Functional modulations of VTA and PFC neuronal activity were primarily associated with intervals when reinforcement was 


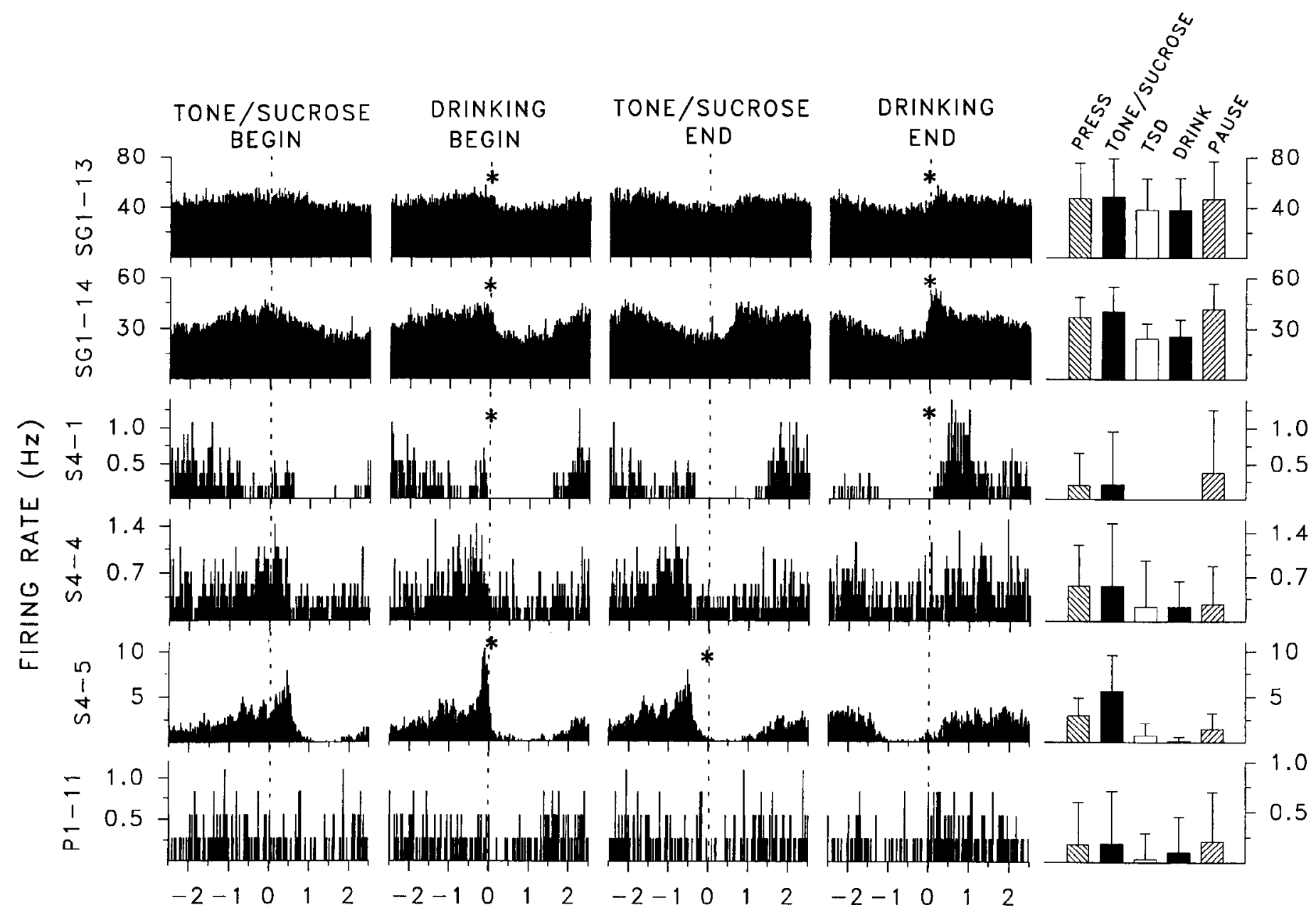

SEC

Figure 5. Six units showing relative decreases in firing rate during drinking behavior. For each unit, four histograms are plotted showing the pattern of unit activity present when spike trains are averaged around Tone/sucrose begin, Drinking begin, Tone/sucrose end, and Drinking end. Significant changes in firing rates in the $500 \mathrm{mscc}$ interval around the node, as detected using the Kolmogorov-Smirnov test, are indicated ${ }^{*}, p<$ 0.001 ). The rightmost graph shows the mean and SD for firing rate within the five behavioral intervals.

available. Neurons recorded in the VTA and PFC displayed strong modulations of firing rate correlated in time with specific elements of motivated behavior. The predominant behaviorally correlated response, observed in 11 of 13 VTA neurons and one of six PFC neurons, took the form of a decrease in firing rate. For six VTA neurons, this decrease corresponded to the interval during which the rat drank sucrose. For five VTA neurons, and one PFC neuron, this decrease began at onset of the tone signaling sucrose delivery, and ended at the time the rat finished drinking. The first group could reflect a simple relationship between neural activity and sensory or motor components of drinking behavior. The second group, however, appears more complex. The firing rate of these neurons decreased at onset of the tone signaling sucrose delivery, but was unchanged by start of drinking or end of the tone signal, increasing only when drinking ended. This pattern coincides with no apparent ongoing sensory or motor activity. It appcars to reflect coding of a an abstract property of the interval when a reinforcer is available. While the significance of this particular coding is not immediately apparent, such abstract coding is consistent with the gen- eral evidence that the PFC and VTA function as part of a secondary or tertiary system mediating motivated behavior.

Interpretation of these findings is complicated by the presence of at least three neuronal subtypes within the VTA. In addition to the DA neurons, GABAergic interneurons are present, as well as nondopaminergic neurons whose projections parallel those of the DA neurons (Deniau et al., 1980; Thierry et al., 1980; Yim and Mogensen, 1980; Swanson, 1982). Within DA neurons, further subtypes may exist. Heterogeneity has been reported in sensitivity of DA neurons to apomorphine (Freeman and Bunney, 1987) and their response to stimulation of afferent pathways (Yim and Mogensen, 1980). Regional variations in cytoarchitecture (Phillipson, 1979a,b) and peptide colocalization (Hokfelt et al., 1980) have also been reported. The GABAergic interneurons are known to directly inhibit VTA DA neurons (Johnson and North, 1992b). The functional significance of the non-DA projecting neurons remains poorly understood. DA neurons show a characteristic electrophysiological profile of a wide (>1.5 msec), frequently polyphasic AP and a low firing rate punctuated by intervals of bursting (Bunney et 


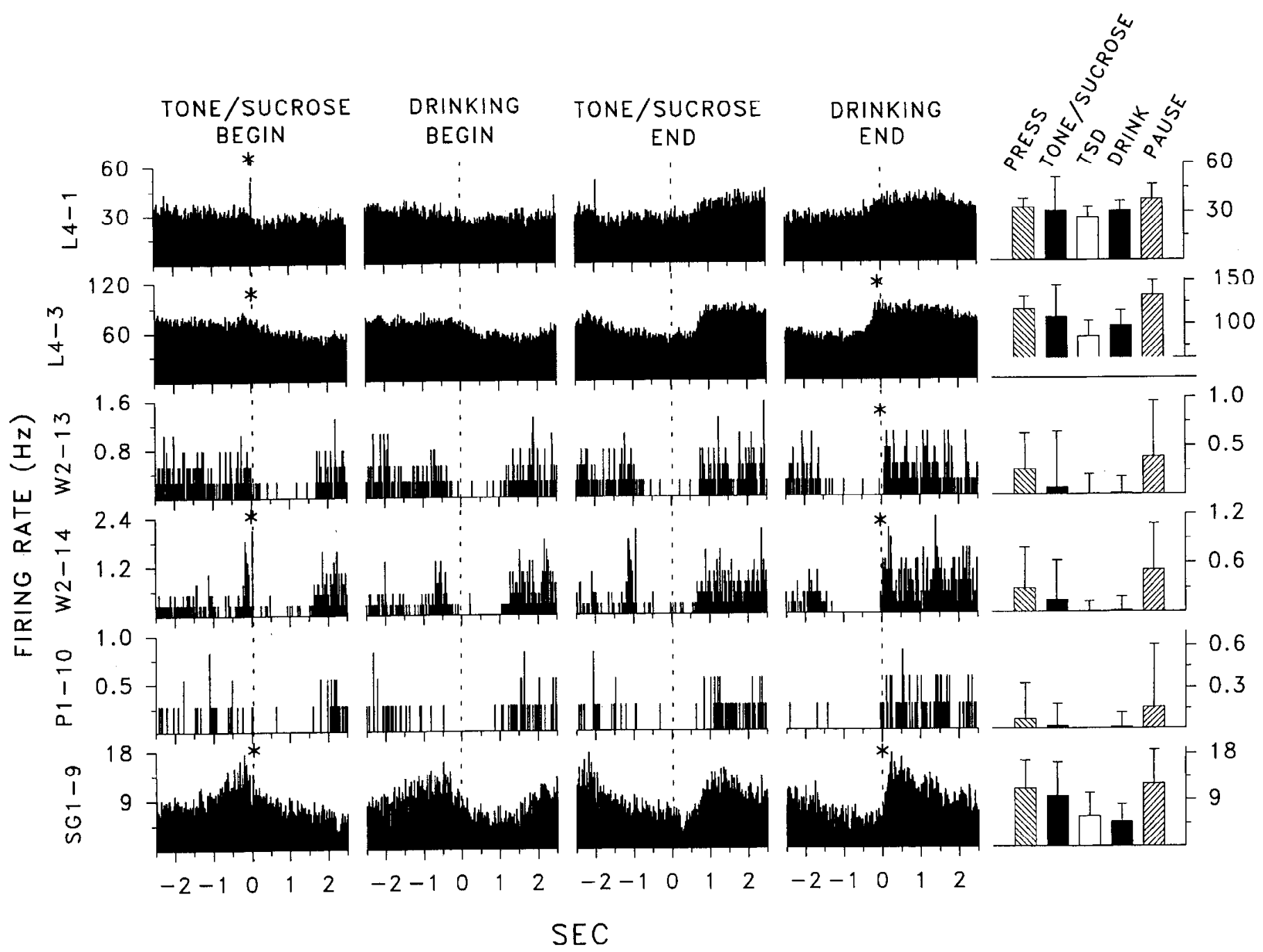

Figure 6. Six units showing relative decreases in firing rate between onset of reward and end of drinking. For each unit, four histograms are plotted showing the pattern of unit activity present when spike trains are averaged around Tone/sucrose begin, Drinking begin, Tone/sucrose end, and Drinking end. Significant changes in firing rates in the $500 \mathrm{msec}$ interval around the node, as detected using the Kolmogorov-Smirnov test, are indicated $(*, p<0.001)$. The rightmost graph shows the mean and SD for firing rate within the five behavioral intervals.

al., 1973; Wang, 1981). Neurons failing to meet these criteria are generally classified as non-DA, but this grouping is a hetcrogeneous collection of non-DA projecting neurons and interneurons, and may include in addition atypical or poorly resolved DA neurons.

The neurons recorded in the present studies did not display the long-duration, polyphasic waveforms typical of DA neurons. Moreover, the responses observed did not provide any basis for division into subgroups that might reflect neuronal subtypes. Specifically, no obvious organization among firing rates, category, and significant response to events emerged (see Table 1). Although the identification of all the various neural elements recorded throughout this circuit is an important eventual goal, our goal here was to focus on the functional correlates of unit activity.

If the patterns of activity observed in the present experiments are typical of DA neurons in the VTA, then the present results suggest that signals indicating acquisition of a reinforcer, or consumption of a reinforcer, are accompanied by a decrease in DA released in NA. This is somewhat surprising, in light of previous evidence suggesting that DA transmission is increased during motivated behavior. However, the studies showing increases have largely utilized methods that rely upon measurements over several minutes to hours. A recently developed technique, high-speed chronoamperometry, allows approximation of neurotransmitter levels with a time resolution on the order of a few seconds. Using this technique to estimate DA levels in rats self-administering heroin, Kiyatkin et al. (1993) observed both a global increase in DA-related signals throughout the selfadministration session, and also a local fluctuation of DA-related signals associated with each injection. Specifically, they found that levels of DA in the NA increased throughout the interval between morphine self-infusions, but dropped abruptly at the moment that the rat pressed the lever to initiate the next morphine injection. This result, in combination with our findings, is consistent with a modified view of the role of DA transmission in motivated behavior. It may be that a general increase in the activity of VTA neurons is associated with situations that present reinforcement opportunities. Such a phenomenon would account for the increases in DA levels observed in target regions over long time scales. The intervals coinciding with acquisition of reinforcement, however, appear to be accompanied by mo- 


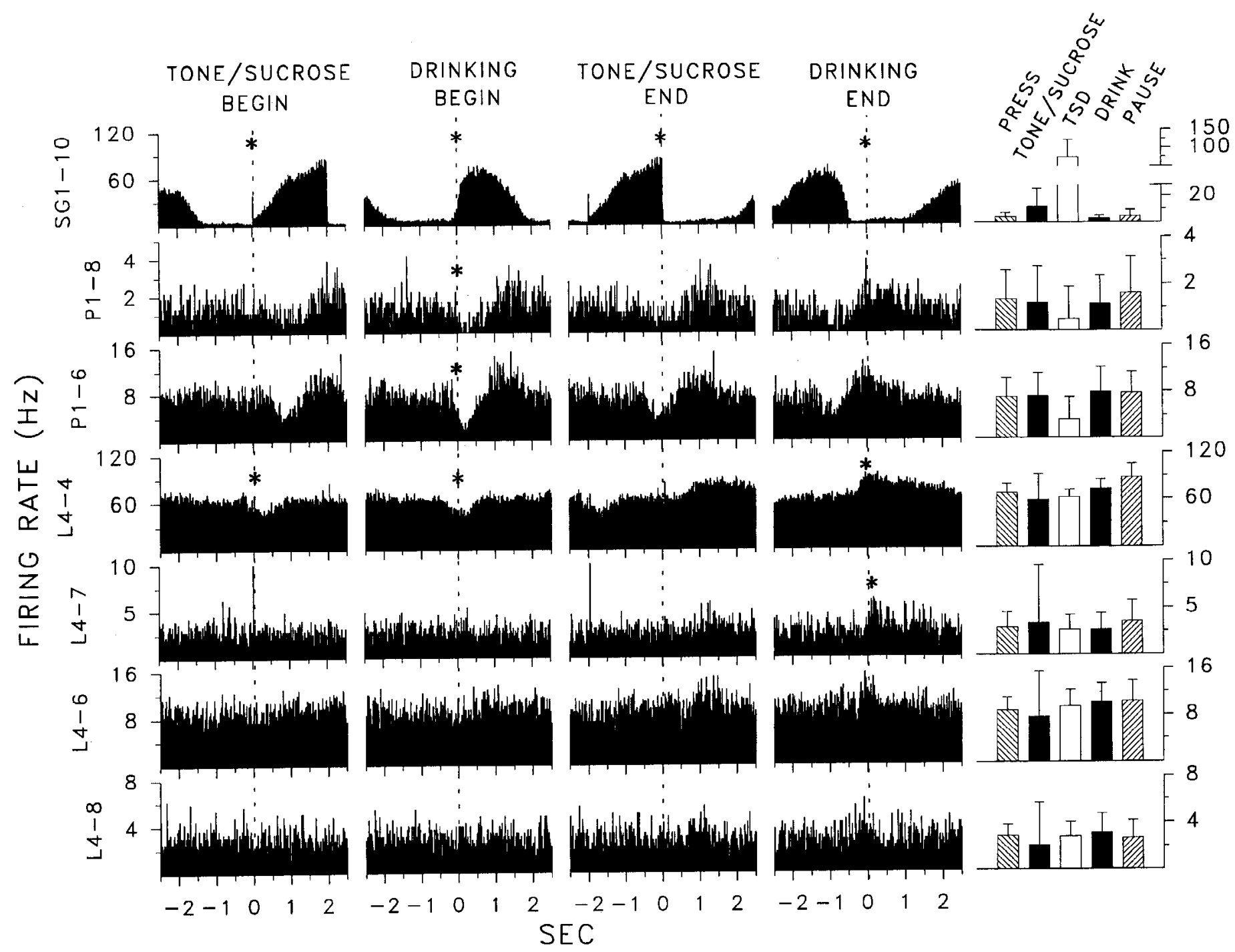

Figure 7. Seven units showing phasic or single interval responses related to ongoing behaviors. For each unit, four histograms are plotted showing the pattern of unit activity present when spike trains are averaged around Tone/sucrose begin, Drinking begin, Tone/sucrose end, and Drinking end. Significant changes in firing rates in the $500 \mathrm{msec}$ interval around the node, as detected using the Kolmogorov-Smirnov test, are indicated (*, $p<0.001$ ). The rightmost graph shows the mean and SD for firing rate within the five behavioral intervals.

mentary decreases in firing of VTA neurons, and release of DA in the NA.

If the primary modulations observed in the current studies reflect the activity of non-DA neurons, however, interpretation is complicated by the heterogeneity of this category, and the relative paucity of data concerned with their functional role in this circuit. If these units were GABAergic interneurons, their activity might be expected to be reciprocal to that of the DA neurons, since they form direct, inhibitory synapses with DA neurons (Johnson and North, 1992a). If these units were nonDA projecting neurons, their interconnections with VTA DA neurons and GABAergic interneurons are not well established; thus, it is not possible to predict their activity relative to other elements of the circuit. Several studies have suggested differential activity of DA and non-DA neurons: VTA DA cells do not show any significant changes in average firing rate over the sleep/wake cycle (Steinfels et al., 1983; Trulson and Preussler, 1984), while non-DA cells display elevated rates during REM and lower rates during slow-wave sleep and in the awake but motionless rat (Miller et al., 1983). Other studies have suggested that increased activity in non-DA neurons can be positively related to changes in DA function, since it is coincident with locomotion stimulated by amphetamine and apomorphine (Olds, $1988 \mathrm{a}, \mathrm{b}$ ), and to enhanced DA metabolism in the NA (Olds, 1991).

Additional findings included phasic coding of discrete events within the behavioral task. In these experiments, we observed a number of other, less frequent responses. Phasic decreases associated with drinking onset were noted ( 2 of 13 VTA, 1 of 6 PFC units). These three units, and one additional unit, also showed brief increases in firing rate associated with Drinking end. Significant excitatory responses were also seen associated with individual lever presses ( 3 of 6 PFC, 2 of 13 VTA units) and with sucrose consumption in the presence of the tone ( 1 of 13 VTA units). This last unit displayed a unique and puzzling pattern of activity. Its rate of firing increased dramatically coincident with the beginning of reward consumption, but decreased abruptly when the tone signaling sucrose delivery ended. While this event had motivational significance (it predicted the approaching end of reinforcement), the rats typically continued 


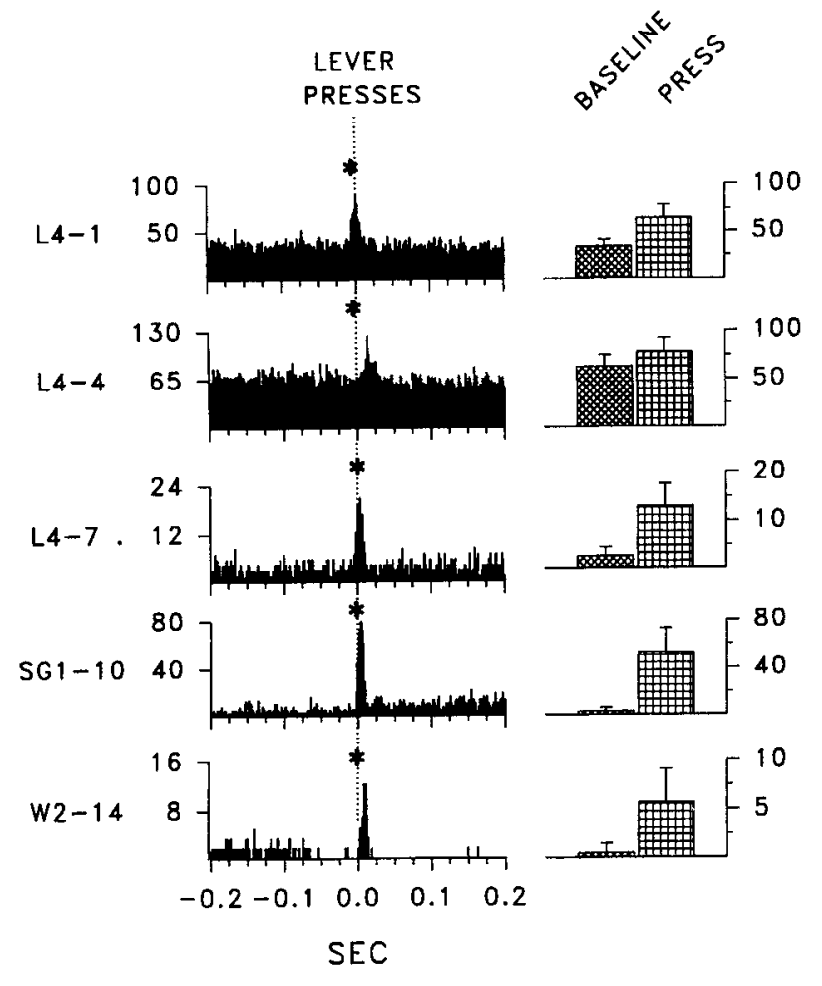

Figure 8. Five units showing phasic responses to lever presses. Perievent histograms are shown on the left. Note that the time scale is much shorter than that used for previous histograms. Mean and SDs for the lever-press response (shown on right) were derived using intervals defined independently for each unit. Baselines reflect an equivalent interval beginning $0.15 \mathrm{sec}$ before the node. The amount of movement of the lever is dependent on the position of the rat's paw on the lever, but ranges between 2 and $3 \mathrm{~mm}$. Movement of the lever activated a relay that could be heard (as a click), and felt through the lever. Two VTA neurons and three PFC neurons showed press responses. Of these responses, three were simultaneous with the closure of the relay, while two lagged this event. These units responded nonselectively to all presses, whether first, intermediate, or last press in a sequence.

drinking for at least $0.5 \mathrm{sec}$ or more. Thus, this neuron strongly coded an event that occurred while the rat was actively engaged in drinking. This unit also showed a increase (albeit relatively small) in firing rate at the end of drinking, suggesting it was also participating in the more typical pattern of coding characteristic of the majority of the observed neurons. It is possible that this reflects the abnormal responsiveness of an injured neuron, as this unit cluster was absent in all subsequent experiments in which this rat participated. Even if this is the case, the responses indicate the presence of inputs providing information about these specific events.

Responses of PFC and VTA neurons were similar, and the small number of neurons sampled did not allow extensive analysis of differences between PFC and VTA neurons. Overall, PFC neurons tended to respond more to sensorimotor events (i.e., the tone, lever presses), while VTA neurons responded to sucrose consumption. However, similar patterns were also present. Note particularly the remarkable similarity between neuron L4E4 (PFC) and neuron P1E6 (VTA) (Fig. 7), recorded in different rats, showing phasic decreases at Drinking begin and increases at Drinking end. PFC neurons L4E3 and L4E1 (Fig. 6) displayed an interval decreasc in firing rate indistinguishable from that of several VTA neurons.
Recordings categorized as multiunit revealed interpretable patterns of activity that did not differ in any conspicuous way from patterns seen in single neuron recordings. The pattern of particular events coded by single neurons was no more consistent nor predictable than that displayed by unit clusters, suggesting that this multievent coding was an actual property of individual neurons, not an ancillary property of a recording reflecting the activity of multiple neurons, each coding a single event. For example, we found several neurons that showed brief bursts associated with individual lever presses. These neurons appeared equally responsive to the first, last, or intervening lever presses in a sequence. Thus, they appeared to be independent of the "sucrose-predicting" value of each press. These units simultaneously coded other elements of ongoing behavior, and there was no predictive relationship between coding of leverpresses and coding of other elements. Overall, these recordings suggest that the various individual neurons in the VTA and target areas act in concert, participating as a group in the coding of multiple elements of the behavioral cycle.

Other investigators have observed modulations of single unit activity in the VTA and related areas associated with reinforcement. Schultz and colleagues noted responses to reinforcers in midbrain DA neurons recorded using driveable electrodes in behaving monkeys. For instance, they found neurons that responded when the monkey touched unseen food, but not nonfood objects (Romo and Schultz, 1989). Although these investigators did not find justification for a sharp functional division among DA neurons, they noted a tendency for reward responses to be more common among VTA DA (A10), as compared to substantia nigra DA (A9) neurons (Schultz et al., 1993). Carelli et al. (1993) recorded from multiple and single units in the nucleus accumbens (NA) in rats lever-pressing for intravenous cocaine. They observed two principal patterns of neural activity associated with behavior. First, some NA neurons increased their firing rates for $1-6 \mathrm{sec}$ immediately following onset of a signaled $6 \mathrm{sec}$ cocaine infusion. These increases did not occur following randomly delivered cocaine administration, so were not the result of a direct pharmacological action of cocaine, nor related to the injection itself. A second group of neurons displayed a short (1-2) sec increase in activity coinciding with the start of drug infusion and also a short burst of activity prior to the first lever press (discussed below). Chang et al. (1994), in a similar study, also observed postcocaine responses in NA neurons recorded in rats self-administering cocaine. In contrast to the study by Carelli et al., these changes were predominantly decreases, and were sustained for as long as several minutes, despite a shorter $(4 \mathrm{sec})$ infusion time.

Single unit activity in the VTA and NA was also modulated during initiation of and execution of goal-directed behavior. In midbrain DA neurons of behaving monkeys, strong neuronal responses were observed to stimuli that signaled when a behavioral response was to be emitted, but not during the behaviors themselves (Schultz, 1986). When the significance of certain stimuli was altered mid-session, neuronal responses shifted to the stimuli with the strongest alerting and reward-predicting properties (Ljungberg et al., 1992; Schultz et al., 1993). In the NA of behaving rats, Carelli et al. (1993) observed neurons displaying a short burst of activity prior to the first lever press. These neurons also displayed a second short (1-2) sec increase in activity coinciding with the start of drug infusion. The initial burst remained associated with the first press when the number of presses required was increased (from 1 to 4 and then to 10). 
Chang et al. (1994) also found changes in firing associated with initiation of lever pressing. A careful behavioral analysis suggested that the beginning of these modulations coincided most closely with the animal orienting to the lever to initiate the next drug administration. The modulations (which were either inhibitory or excitatory) were sustained until the rat completed a lever press. Such alterations in firing were not seen associated with similar movements unrelated to lever pressing.

In the NA, neurons with responses to both initiation of goaldirected behavior, and with reinforcement, were frequently $o b$ served. Chang et al. (1994) reported that two-thirds of the NA neurons that showed orienting-related anticipatory responses also showed postcocaine responses. In these neurons, the postcocaine inhibition was blocked by D1 and D2 antagonists at doses that extinguished lever pressing. This result suggests two related points. First, that the postcocaine inhibition in neurons with orienting-related responses may reflect a direct pharmacological action of cocaine (presumably by increasing synaptic DA). Second, this inhibition may reflect a central representation of reinforcement, since its disappearance coincides with extinction of the lever press response. However, in neurons that showed postcocaine inhibitions only, the antagonists had no effect. In the study by Carelli et al. (1993), all neurons displaying an initiation response (a short burst of activity prior to the first lever press) also displayed a second short (1-2) sec increase in activity coinciding with the start of drug infusion. This pattern was not observed initially; its appearance coincided with the development of stable rates of self-administration of cocaine. These investigators note that the development of stable selfadministration behavior has been shown to maintain a specific level of DA in the NA, and may reflect titration to a desired subjective effect of cocaine (Pettit and Justice, 1991).

In general, these data present a complex picture of the events and behaviors that serve as effective modulators of unit activity in the VTA and NA. While supporting the role of the VTA-NA circuil in initiation and execution of goal-directed behavior as well as acquisition of reinforcement, each of these studies described findings unique in details of form and timing of neural modulations correlated with behavior. These differences may arise largely from differences in the behavioral context of particular tasks, and careful behavioral analyses may be indispensable to achieve any real understanding of the significance of the observed neural correlates of behavior. For example, our own data was substantially less comprehensible until we had determined exactly when the rats began and finished drinking.

Behavioral analysis of single unit activity suggests a much more subtle modulation of VTA-NA activity than that implied by studies using other techniques. Measures of neural activity in behaving animals present a very different view of the activity of these neurons than predicted by studies using anesthetized animals, or using measurements that yield average values over minutes or hours. Such studies have suggested a substantial increase in DA release that is maintained throughout the session. A reflection of these changes would be expected to be observable in unit activity in the VTA and NA, either in the form of tonic alterations of basal firing rates, or in phasic increases consistent with increased DA impulse flow. However, we did not observe any within-session increases in average firing rate of VTA neurons. Neither Carelli et al. (1993) nor Chang et al. (1994) observed an overall inhibition of NA neurons. Moreover, these investigators did not observe consistent evidence for a pure pharmacological effect of cocaine on NA neurons during self- administration, although in anesthetized animals, cocaine inhibits these neurons (White, 1990; White et al., 1992). The behaviorally correlated changes were also not easily interpretable-some NA neurons appeared to show increases in firing rate associated with cocaine infusion, consistent with a decrease in DA input (and with our findings). Other NA neurons, however, showed cocaine infusion-related decreases. Wolske et al. (1993), recording from NA neurons during intracranial selfstimulation of the medial forebrain bundle, also observed both excitatory and inhibitory responses to stimulation. Thus, the timing of event-related changes in neural activity appears to be more informative than the direction of these changes. It appears that in awake, behaving animals, individual neurons do not show fixed responses predictable from their anatomical relationships and pharmacology, but instead a complex and unique pattern of activity that is far more dependent on the simultaneous activity of other elements in the circuit. In order to understand the contribution of the motivational system to ongoing behavior, it is necessary to focus on the information carried by all elements in the system, and examine the function of this circuit in a behavioral context.

Is it possible to reconcile the evidence suggesting a substantial enhancement of DA levels during motivated behavior with the evidence of relatively modest, restricted, and bidirectional fluctuations in firing rate of single neurons? We offer the following view, which suggests two simultaneous actions of DA in motivated behavior. First, the well-established gross increases in DA levels reflect a global action of DA, whereby overall DA levels positively correlate with the relative motivational state of the animal. As these increased levels do not appear to alter the activity of neurons recorded in the NA, their primary action might instead be to modulate responses of NA neurons to other inputs, such as those from amygdala or hippocampus. Evidence for such a modulatory role for VTA DA has been reported (Yim and Mogensen, 1982). Second, within a given motivational context, DA has a separate, local role. Specifically, increases in the activity of VTA DA neurons should correlate directly with increases in the probability of initiation of goal-directed behavior. Once action is initiated, however, the role of the mesocorticolimbic DA system is completed, and the corresponding levels of DA drop. Primary control of behavior shifts downstream to systems more directly engaged in execution of motor acts. Similar ideas have been advanced, for instance Schultz (1992, p. 135) proposed that "responses of dopamine neurons are involved in determining the probability and intensity of behavioral reactions, the basic measure of motivation."

Conclusions. In summary, recordings from neurons in the VTA and PFC in rats engaged in a simple operant task revealed strong modulation of neural activity associated with motivated behavior. These modulations took the form of interval decreases during consumption of a reinforcer ( 6 of 13 VTA units), interval decreases during availability and consumption of a reinforcer (4 of 13 VTA units, 2 of 6 PFC units), and phasic changes associated with the beginning or end of events and behaviors (2 of 13 VTA units, 4 of 6 PFC units), or lever presses (2 of 13 VTA units, 3 of 6 PFC units). Several units appeared to simultaneously encode independent information (e.g., lever presses as well as end of drinking). As a group, the activity of these neurons appeared to encode information about all primary attributes of the task, both within defined intervals and transitions between intervals. The predominant pattern of coding for reward availability and consumption within this group of neurons 
is consistent with the participation of the VTA and PFC in a motivational system mediating goal-directed behavior.

\section{References}

Blackburn JR, Phillips AG, Jakubovic A, Fibiger HC (1986) Increased dopamine metabolism in the nucleus accumbens and striatum following consumption of a nutritive meal but not a palatable nonnutritive saccharin solution. Pharmacol Biochem Behav 25:10951100.

Blackburn JR, Phillips AG, Fibiger HC (1987) Dopamine and preparatory behavior. I. Effects of pimozide. Behav Neurosci 101:352360.

Blackburn JR, Phillips AG, Jakubovic A, Fibiger HC (1989a) Dopamine and preparatory behavior. II. A neurochemical analysis. Behav Neurosci 103:15-23.

Blackburn JR, Phillips AG, Fibiger HC (1989b) Dopamine and preparatory behavior. III. Effects of metoclopromide and thioridazine. Behav Neurosci 103:903-906.

Blundell JE, Strupp BJ, Latham CJ (1977) Pharmacological manipulation of hoarding: further analysis of amphetamine isomers and pimozide. Physiol Psychol 5:394-409.

Bozarth MA, Wise RA (1986) Involvement of the ventral tegmental dopamine system in opioid and psychomotor stimulant reinforcement. In: National Institute on Drug Abuse research monograph 67, Problems of drug dependence, 1985 (Harris LS, ed), pp 190-196. Washington, DC: U.S. Government Printing Office.

Bunney BS, Walters JR, Roth RH, Aghajanian GK (1973) Dopaminergic neurons: Effect of antipsychotic drugs and amphetamine on single cell activity. J Pharmacol Exp Ther 185:560-571.

Carboni E, Imperato A, Perezzani L, Di Chiara G (1989) Amphetamine, cocaine, phencyclidine and nomifensine increase extracellular dopamine concentrations preferentially in the nucleus accumbens of freely moving rats. Neuroscience 28:653-661.

Carelli RM, King VC, Hampson RE, Deadwyler SA (1993) Firing patterns of nucleus accumbens neurons during cocaine self-administration in rats. Brain Res 626:14-22.

Chang JY, Sawyer Sf, Lee RS, Woodward DJ (1994) Electrophysiological and pharmacological evidence for the role of the nucleus accumbens in cocaine self-administration in freely moving rats. $J$ Neurosci 14:1224-1244.

Chen JP, Marmur R, Pulles A, Paredes W, Gardner EL (1993) Ventral tegmental microinjection of delta(9)-tetrahydrocannabinol enhances ventral tegmental somatodendritic dopamine levels but not forebrain dopamine levels-evidence for local neural action by marijuana's psychoactive ingredient. Brain Res 621:65-70.

Clody DE, Carlton PE (1980) Stimulus efficacy, chlorpromazine, and schizophrenia. Psychopharmacology 34:1127-1131.

Deniau JM, Thierry AM, Féger J (1980) Flectrophysiological identification of mesencephalic ventromedial tegmental (VMT) neurons projecting to the frontal cortex, septum and nucleus accumbens. Brain Res 189:315-326.

de Wit H, Wise RA (1977) Blockade of cocaine reinforcement in rats with the dopamine receptor blocker pimozide, but not with the noradrenergic blockers phentolamine or phenoxybenzamine. Can J Psychol 31:195-203.

Freeman AS, Bunney BS (1987) Activity of A9 and A10 dopaminergic neurons in unrestrained rats: further characterization and effects of apomorphine and cholecystokinin. Brain Res 405:46-55.

Goeders NE, Smith JE (1993) Intracranial cocaine self-administration into the medial prefrontal cortex increases dopamine turnover in the nucleus accumbens. J Pharmacol Exp Ther 265:592-600.

Goeders NF, I ane JD, Smith JE (1984) Self-administration of methionine enkephalin into the nucleus accumbens. Pharmacol Biochem Behav 20:451-455.

Heffner TG, Hartman JA, Seiden LS (1980) Feeding increases dopamine metabolism in the rat brain. Science 208:1168-1170.

Hoebel BG, Monaco AP, Hernandez L, Aulisi EF, Stanley BG, Lenard $L$ (1983) Self-injection of amphetamine directly into the brain. Psychopharmacology 81:158-163.

Hokfelt T, Skirboll LR, Rehfeld JF, Goldstein M, Markey K, Dann K (1980) A subpopulation of mesencephalic dopamine neurons projecting to limbic areas contains a cholecystokinin-like peptide: evidence from immunohistochemistry combined with retrograde tracing. Neuroscience 5:2093-2124.
Imperato A, Di Chiari G (1986) Preferential stimulation of dopaminerelease in the nucleus accumbens of freely moving rats by ethanol. J Pharmacol Exp Ther 239:219-228.

Imperato A, Mulas A, Di Chiara G (1986) Nicotine preferentially stimulates dopamine release in the limbic system of freely moving rats. Eur J Pharmacol 132:337-338.

Johnson SW, North RA (1992a) Opioids excite dopamine neurons by hyperpolarization of local interneurons. J Neurosci 12:483-488.

Johnson SW, North RA (1992b) Two types of neurone in the rat ventral tegmental area and their synaptic inputs. J Physiol (Lond) 450:455-468.

Kiyatkin EA, Wise RA, Gratton A (1993) Drug- and Behavior-associated changes in dopamine-related electrochemical signals during intravenous heroin self-administration in rats. Synapse 14:60-72.

Le Moal M, Stinus L, Simon SC, Tassin J-P, Thierry AM, Blanc G, Glowinski J, Cardo B (1977) Behavioral effects of a lesion in the ventral mesencephalic tegmentum: evidence for involvement of A10 dopaminergic neurons. In: Advances in biochemical psychopharmacology (Costa E, Gessa GL, eds), pp 237-245. New York: Raven.

Ljungberg T, Apicella P, Schultz W (1992) Responses of monkey dopamine neurons during learning of behavioral reactions. J Neurophysiol 67:145-163.

Lyness WH, Friedle NM, Moore KE (1979) Destruction of dopaminergic nerve terminals in nucleus accumbens: effect on D-amphetamine self-administration. Pharmacol Biochem Behav 11:553-560.

McCullough LD, Salamone JD (1992) Anxiogenic drugs beta-CCE and FG 7142 increase extracellular dopamine levels in nucleus accumbens. Psychopharmacology 109:379-382.

Miller JD, Farber J, Gatz P, Roffwarg H, German DC (1983) Activity of mesencephalic dopamine and non-dopamine neurons across stages of sleep and waking in the rat. Brain Res 273:133-141.

Moore GP, Perkel DH, Segundo JP (1966) Statistical analysis and functional interpretation of neuronal spike data. Annu Rev Physiol 28:493-522.

Olds ME (1982) Reinforcing effects of morphine in the nucleus accumbens. Brain Res 237:429-440.

Olds ME (1988a) Correlation between the discharge rate of non-dopaminergic neurons in substantia nigra and ventral tegmental arca and the motor activity induced by apomorphine. Neuroscience 24 : $465-476$.

Olds ME (1988b) Amphetamine-induced increase in motor activity is correlated with higher firing rates of non-dopamine neurons in substantia nigra and ventral tegmental area. Neuroscience 24:477490.

Olds ME (1991) Enhanced dopamine metabolism in accumbens leads to motor activity and concurrently to increased output from nondopamine neurons in ventral tegmental area and substantia nigra. Physiol Behav 51:39-50.

Panksepp J (1982) Toward a general psychobiological theory of emotions. Behav Brain Sci 5:407-467.

Pettit HO, Justice JB Jr (1991) Effect of dose of cocaine on selfadministration bchavior and dopaminc levels in the nuclcus accumbens. Brain Res 539:94-102.

Pettit HO, Ettenberg A, Bloom FE, Koob GF (1984) Destruction of dopamine in the nucleus accumbens selectively attenuates cocaine but not heroin self-administration in rats. Psychopharmacology 84 : 167-178.

Phillips AG, Pfaus JG, Blaha CD (1991) Dopamine and motivated behavior: insights provided by in vivo analyses. In: The mesolimbic dopamine system: from motivation to action (Willner P, Scheel-Kruger J, eds), pp 200-224. Chichester: Wiley.

Phillipson OT (1979a) The cytoarchitecture of the interfascicular nucleus and ventral tegmental area of Tsai in the rat. J Comp Neurol 187:85-98.

Phillipson OT (1979b) A Golgi study of the ventral tegmental area of Tsai and interfascicular nucleus in the rat. J Comp Neurol 187:99116.

Roberts DCS, Corcoran ME, Fibiger HC (1977) On the role of ascending catecholaminergic systems in intravenous self-administration of cocaine. Pharmacol Biochem Behav 6:615-624.

Romo R, Schultz W (1989) Somatosensory input to dopamine neurones of the monkey midbrain: responses to pain pinch under anaesthesia and to active touch in behavioural context. Prog Brain Res 80:473-478.

Salamone JD (1991) Behavioral pharmacology of dopamine systems: 
a new synthesis. In: The mesolimbic dopamine systems: from motivation to action (Willner P, Scheel-Kruger J, eds), pp 599-613. Chichester: Wiley.

Schultz W (1986) Responses of midbrain dopamine neurons to behavioral trigger stimuli in the monkey. J Neurophysiol 56:1439-1461.

Schultz W (1992) Activity of dopamine neurons in the behaving primate. Semin Neurosci 4:129-138.

Schultz W, Apicella P, Ljungberg T (1993) Responses of monkey dopamine neurons to reward and conditioned stimuli during successive steps of learning a delayed response task. J Neurosci 13:900913.

Spanagel R, Herz A, Shippenberg TS (1990) Identification of the opioid receptor types mediating beta-endorphin-induced alterations in dopamine release in the nucleus accumbens. Eur J Pharmacol 190:177184.

Spanagel R, Herz A, Shippenberg TS (1991) Modulation of the mesolimbic dopaminergic system by beta-endorphin-(1-27) as assessed by microdialysis. Eur J Pharmacol 200:319-324.

Steinfels GF, Heym J, Strecker RE, Jacobs BL (1983) Behavioral correlates of dopaminergic unit activity in freely moving cats. Brain Res 258:217-228.

Swanson LW (1982) The projections of the ventral tegmental area and adjacent regions: a combined fluorescent retrograde tracer and immunofiuorescence study in the rat. Brain Res Bull 9:321-353.

Thierry AM, Tassin JP, Blanc G, Glowinski J (1976) Selective activation of the mesocortical DA system by stress. Nature 263:242-244.

Thierry AM, Deniau JM, Herve D, Chevalier G (1980) Electrophysiological evidence for non-dopaminergic mesocortical and mesolimbic neurons in the rat. Brain Res 201:210-214.

Trulson ME, Preussler DW (1984) Dopamine-containing ventral tegmental neurons in freely moving cats: activity during the sleep-waking cycle and effects of stress. Exp Neurol 83:367-377.
Wang RY (1981) Dopaminergic neurons in the rat ventral tegmental area. I. Identification and characterization. Brain Res 3:123-140.

White FJ (1990) Electrophysiological basis of the reinforcing effects of cocaine. Behav Pharmacol 1:303-315.

White FJ, Henry DJ, Xiu-tu H, Jeziorski M, Ackerman JM (1992) Electrophysiological effects of cocaine in the mesoaccumbens dopamine system. In: Cocaine: pharmacology, physiology and clinical strategies (Lakoski JM, Galloway MP, White FJ, eds), pp 261-289. Boca Raton, FL: CRC.

Wise RA, Rompre P-P (1989) Brain dopamine and reward. Annu Rev Psychol 40:191-225.

Wolske M, Rompre PP, Wise RA, West MO (1993) Activation of single neurons in the rat nucleus accumbens during self-stimulation of the ventral tegmental area. J Neurosci 13:1-12.

Yim CY, Mogenson GJ (1980a) Electrophysiological studies of neurons in the ventral tegmental area of tsai. Brain Res 181:301-313.

Yim CY, Mogensen GJ (1980b) Effect of picrotoxin and nipecotic acid on inhibitory response of dopaminergic neurons in the ventral tegmental area to stimulation of the nucleus accumbens. Brain Res 199: $466-472$.

Yim CY, Mogensen G.J (1982) Response of nucleus accumbens neurons to amygdala stimulation and its modification by dopamine. Brain Res 239:401-415.

Yokel RA, Wise RA (1975) Increased lever pressing for amphetamine after pimozide in rats: implications for a dopamine theory of reward. Science 187:547-549.

Yoshimoto K, McBride WJ, Lumeng L, Li TK (1992) Alcohol stimulates the release of dopamine and serotonin in the nucleus accumbens. Alcohol 9:17-22. 